\title{
Relationships Among Attitude Toward Leisure, Satisfaction With Leisure Policies, Satisfaction With Leisure Activities, And Happiness In Korean Caregivers For Young Children
}

Jieun Yoo ( $\nabla$ msje9295@anyang.ac.kr)

Anyang University

\section{Research Article}

Keywords: attitude toward leisure, satisfaction with leisure policy, satisfaction with leisure activities, happiness

Posted Date: March 7th, 2022

DOI: https://doi.org/10.21203/rs.3.rs-1336934/v1

License: (c) (i) This work is licensed under a Creative Commons Attribution 4.0 International License. Read Full License 


\section{Abstract}

This study investigated the effect of attitude toward leisure and satisfaction with leisure policy on satisfaction with leisure activities and level of happiness in Korean caregivers for young children. Data were collected from 864 participants (397 men and 467 women) using the 2018 National Leisure Activity Survey (NLAS). The results showed that there were no significant differences between male and female caregivers in terms of satisfaction with leisure policy, satisfaction with leisure activities, and level of happiness. Women had more positive attitudes toward leisure. Satisfaction with leisure activities mediated the relationship between attitude toward leisure, satisfaction with leisure policy, and level of happiness; there were no significant differences between men and women with regard to the variables. The study suggests that attitude toward leisure and satisfaction with leisure policy promote the happiness of Korean caregivers for young children.

\section{Introduction}

In the process of achieving economic development, South Korea has prioritized the sense of accomplishment that comes through work (Han et al., 2019); leisure activities used to be thought of only as ancillary means of improving labor productivity. Over the past decades, many Koreans have had negative attitudes about leisure activities that did not seem productive. Due to rapid economic development led by the government, incomes increased and the standard of living greatly improved, but Koreans' satisfaction with life and their level of happiness remained low compared to other countries (Doh \& Chung, 2020; Helliwell et al., 2019; World Bank, 2021). Most Koreans did not feel happy while engaging in leisure activities.

As Koreans have recently become increasingly interested in the topic of happiness, leisure has come into focus as a way of improving well-being (Doh \& Chung, 2020; Han et al., 2020). Growth in the number of leisure-related studies has contributed to life satisfaction for individuals (Ragheb \& Griffith, 1982; Ray, 1979; Riddick, 1986) and families (Alan, 2009; Holman \& Jacquart, 1988; Orthner \& Mancini, 1990; Zabriskie \& McCormick, 2003) and the body of Korean literature related to the effects of leisure on life satisfaction is also growing (Doh \& Chung, 2020; Jeong \& Won, 2002; Kim \& Lee, 2011). However, previous leisure studies focused on participation in leisure activities and its effect on life satisfaction, and studies related to leisure attitudes and leisure policies were insufficient in number. Additionally, most Korean researchers have indicated that participation in leisure activities has been associated with a higher quality of life among Korean adolescents (Lee, 2005), college students (Lee, 2010), and older adults (Son, 2017), but few researchers have studied caregivers for young children in Korea. Therefore, it would be meaningful to explore the relationships among attitude toward leisure, satisfaction with leisure policy, satisfaction with leisure activities, and happiness in Korean caregivers for young children.

\section{Attitude toward Leisure}


Veblen (1994) regarded leisure as a symbol of wealth and an activity different from work and/or unproductively spent time. Similarly, some researchers have approached leisure (as opposed to work hours) as a time to pursue pleasure, engage in voluntary activities, and experience a feeling of freedom (Edginton, \& Chen, 2008; Leitner \& Leitner, 2004; Stebbins, 2009). Others viewed leisure's primary function as preparation for work, or even as compensation for the alienating effect of work (Meyer \& Niezgoda, 2018). Attitude toward leisure is defined as a willingness or predisposition to engage in leisure activities (Ragheb \& Beard 1982). Attitudes toward leisure include beliefs, feelings, perceptions, knowledge, and behavioral components associated with leisure (Stockdale, 1985; Teixeira \& Freire, 2013). In Korea, attitude toward leisure is usually assessed based on individuals' perceptions or beliefs about participating in leisure activities. These belief systems have changed because of social changes in Korea (Han et al., 2020). In the past, leisure was recognized and enjoyed as a subsidiary means to increase the production and efficiency of labor; however, leisure is now viewed as something that contributes to personal happiness and life satisfaction (Jeung \& Yoon, 2014; Han et al., 2020).

One's attitude toward leisure affects one's satisfaction with one's leisure time and activities. Some studies have shown that a positive attitude toward leisure is positively associated with a desire to participate in leisure activities (Ragheb \& Tate, 1993), which results in the development of satisfaction with leisure activities and time (Haworth \& Lewis, 2005; Kim et al., 2015). When an individual's perceptions or emotions about leisure are positive, their satisfaction with leisure activities and time and with quality of life improve (Kim, 2009). In addition, other Korean research supports the idea that a positive attitude toward leisure is positively correlated with satisfaction with leisure activities and time among college students (Choi \& Yoo, 2017; Kim et al., 2015).

\section{Satisfaction with Leisure Policy}

Leisure policy acknowledges the demand for leisure and systematically devises a plan to support leisure activities in accordance with individuals' basic rights (Han et al., 2020). Leisure policies come from leisure-related government agencies that aim to increase people's participation in leisure, create leisure spaces, administrate leisure policy processes, and secure leisure environments (Cho, 2014). Since 1960, when overcoming national poverty was a top priority, Korea has pursued a labor-intensive production policy that relies on limited human resources. After growing as a labor-production-oriented society, Korea has established various leisure policies to reduce working hours and expand leisure time and activities to improve the quality of life for individuals (Han et al., 2020). For example, adopting policies such as five days or 52 hours of work per week and expanding the alternative holiday system increased individual leisure activities (Ministry of Culture, Sports, and Tourism, 2016).

Although environments where people can engage in leisure have improved and more public leisure facilities have been created through these policies, questions have arisen about the effect of these policies on the satisfaction that comes from leisure in Korea. The goal of the leisure policies was to improve the quality of life of individuals, but in practical terms, it was a supplier-oriented policy that did 
not take into account those who participate in leisure activities in Korea (Han et al., 2020). Therefore, the recognition and the evaluation of leisure policies have become important research topics as they relate to satisfaction with leisure activities. Some Korean research found a positive relationship between satisfaction with leisure policy and satisfaction with leisure activities (Han et al., 2019; Heo, 2014), but related studies are still scarce.

\section{Satisfaction with Leisure and Happiness}

Satisfaction with leisure is understood as an individual's positive evaluation of participating in leisure activities (Ragheb \& Tate, 1993). According to Beard and Ragheb (1980; Ateca-Amestoy, 2011), satisfaction with leisure is defined as positive personal perceptions or feelings derived from participating in leisure activities and resulting in the fulfillment of personal needs. Happiness is considered essential to an individual's life. According to the Greek philosopher Aristotle, a happy life is a virtuous life (McMahon, 2006). The term happiness is defined as "positive affect and subjective well-being" (Myers \& Diener, 1995; Diener et al., 2002) and is influenced by genetics, circumstances, and attitudes (Seligman, 2002). The concept of happiness is also related to life satisfaction or evaluation, subjective well-being, eudaimonia (i.e., psychological well-being), quality of life, or affect (Cho, 2017).

A considerable amount of literature has shown a positive association between satisfaction with leisure activities and psychological well-being, life satisfaction, or happiness. According to Freire and Teixeira (2018), leisure satisfaction has a direct effect on self-esteem, satisfaction with life, and psychological well-being. Kaya (2016) found a positive association between satisfaction with leisure activities and happiness among college students. Leisure satisfaction influences life satisfaction in Korean adolescents (Shin \& You, 2013). Wang et al.'s (2008) study showed, with regard to online games, a significant positive relationship between the physiological and aesthetic elements of leisure satisfaction and life satisfaction for adolescents. All these studies provide empirical evidence that leisure satisfaction enhances happiness.

Recently, leisure-related research in non-Western countries has been increasing, but few studies have researched leisure in the context of caregivers in Korea. Leisure has had an impact on the lives of young children and their caregivers (Doh, 2014; Moon, 2001). The happiness of caregivers affects children's well-being and social and emotional development (Kim, 2019). Leisure was found to play a role in ultimately improving the psychological satisfaction of parents and enhancing family health by preventing and/or alleviating stress (Choi, 2008). Therefore, research on the relationship between leisure and happiness in Korean caregivers for young children is essential.

\section{Hypothesized model of attitude toward leisure, satisfaction with leisure policy, satisfaction with leisure activities, and happiness}


Based on previous studies, it is plausible that one's attitude toward leisure and satisfaction with leisure policy would lead to satisfaction with leisure activities and that satisfaction, in turn, would increase happiness. Therefore, this study aimed to investigate the hypothesized full mediational model in which attitude toward leisure, satisfaction with leisure policy, and happiness are fully mediated by satisfaction with leisure activities. Level of happiness has been reported differently by the different sexes. Subjective well-being was shown to be higher in women than in men, but the difference is not known to be significant (Frey \& Stutzer, 2002). Some Korean studies have shown gender differences in levels of happiness (Jung et al., 2019; Kim et al., 2003). The present study sought to explore gender differences in the latent variables and the mediating pathway from attitude toward leisure and satisfaction with leisure policy to level of happiness, via satisfaction with leisure activities; structural equation modeling (SEM) with a nationally representative sample of Korean caregivers for young children (see Figure 1), latent mean analysis (LMA), and multigroup structural model analysis were used for the purpose. The results would increase researchers' understanding of the link between leisure and happiness and provide useful insights to improve the relationship between Korean caregivers and the young children in their care.

\section{Method}

\section{Procedure}

This study uses secondary data analysis from the 2018 National Leisure Activity Survey (NLAS), which collected data from a nationally representative sample of Korean individuals consisting of 10,496 participants over 15 years of age living in 17 cities and provinces. The NLAS involved a set of assessment modules designed by the Ministry of Culture, Sports, and Tourism to provide trend data reflecting changes in lifestyle and quality of life; the analysis reflects the status of leisure activities affecting demand for leisure according to various and changing domestic leisure environments. The NLAS consisted of a one-on-one interview by an investigator, and the survey period was from October 1 , 2018 , to November 30, 2018. The 2018 NLAS was performed under approval from Statistics Korea (Approval Number 113014). The raw data is publicly available from the Statistics Korea website (https://mdis.kostat.go.kr/index.do).

\section{Sample}

For the current study, participants were selected from among the respondents in the 2018 NLAS. The selected families consisted of caregivers (parents, mothers, fathers, grandparents, grandmothers, and grandfathers) aged 20-70 years with a preschool-aged child or children (3-6 years old). The sample included 864 participants (397 men and 467 women). The proportions of participants in their $20 \mathrm{~s}, 30 \mathrm{~s}, 40 \mathrm{~s}, 50 \mathrm{~s}, 60 \mathrm{~s}$, and 70 s or older were $5.1 \%, 68.1 \%, 25.2 \%, 0.9 \%, 0.6 \%$, and $0.1 \%$, respectively. Of the total sample, $369(42.7 \%)$ resided in metropolitan cities, $314(36.3 \%)$ in medium-size cities, and $181(20.9 \%)$ in rural areas. Participants' education level varied as follows: $5(0.6 \%)$ had completed middle school, 227 (26.3\%) had completed high school, and 632 (73.1\%) had a Bachelor's degree or a graduate 
degree. They participated in six leisure activities-cultural and art-viewing activities, cultural and artistic participation activities, tourism, hobbies and entertainment, relaxation, and social and other activities (a category that included 87 kinds of leisure activities). The leisure types are presented in Table 1.

[Table 1 near here]

\section{Variables}

\section{Attitude toward Leisure}

Attitude toward leisure measured the perception of leisure, using two items. Participants were asked to respond to the following questions: "Do you think leisure activities are an essential requirement for life?" and "Do you think leisure activities have a positive effect on your life (happiness, health, family relationships, etc.)?" on a scale of 1 to 7 ( $1=$ strongly disagree, 7 = strongly agree). The Cronbach's alpha coefficient for attitude toward leisure was 0.841 .

\section{Satisfaction with Leisure Policy}

Satisfaction with leisure policy measured the satisfaction with the legal system and the infrastructure for leisure, using two items. Participants were asked to respond to the following questions: "Are you satisfied with the legal system related to leisure activities?" and "Are you satisfied with the leisure infrastructure?" on a scale of 1 to 7 ( 1 = very dissatisfied, 7 = very satisfied). The Cronbach's alpha coefficient for satisfaction with leisure policy was 0.881 .

\section{Satisfaction with Leisure Activities}

Satisfaction with leisure activities was measured using two items. Participants were asked to respond to the statements, "Are you satisfied with your overall leisure life?" and "Are you satisfied with the leisure activities you have participated in most in the past year?" on a scale of 1 to $7(1=$ very dissatisfied to $7=$ very satisfied). The reliability coefficient, using Cronbach's alpha for leisure satisfaction was 0.734 .

\section{Happiness}

Happiness was measured using a single item. Participants were asked to respond to the question, "How happy do you think you are now?" on a scale of 1 to 10 ( 1 = very unhappy, $10=$ very happy).

\section{Overview of Analysis}


For this study analysis, PASW 18.0 was used for the general characteristics of the participants and leisure activities, reliability, and correlation analysis of the measurement instruments. AMOS 18.0 was used for the structural equation modeling (SEM) to provide the hypothesized structural relationships among latent variables. This study evaluated the full mediation model of the relationship between attitude toward leisure, satisfaction with leisure policy, satisfaction with leisure activities, and happiness. In addition, this study conducted a latent mean analysis (LMA) and multigroup structural analysis to find differences between male and female groups (Hong et al., 2003). Latent mean analysis can estimate the latent mean for males; the latent mean for females was set at 0. For LMA, invariance tests (e.g., configural invariance, metric invariance, and scalar invariance) were conducted in the hierarchical ordering of nested models. After the assessment of LMA was complete, a multigroup structural analysis was performed. The model fit with the maximum likelihood (ML) method and was evaluated using two relative-model fit criteria (Turker-Lewis index [TLI] and comparative fit index [CFI]), one absolute model fit criterion (root meansquare error of approximation [RMSEA]), and the chi-squared difference test ( $\triangle \chi^{2}$ test).

\section{Results}

\section{Descriptive statistics}

Descriptive statistics with mean, standard deviations, skewness, kurtosis, and correlations for all variables are shown in Table 2. Overall, attitude toward leisure and satisfaction with leisure policy showed a positive correlation with satisfaction with leisure activities in both male and female caregivers. Two variables associated with attitude toward leisure were not correlated with satisfaction with leisure policy variables, but satisfaction with leisure activities was correlated with happiness in both groups. All significant correlations were positive. This is consistent with previous studies showing that attitude toward leisure and satisfaction with leisure policy are positively correlated with satisfaction with leisure activities (Choi \& Yoo, 2017; Han et al., 2019; Haworth \& Lewis, 2005; Heo, 2014; Kim et al., 2015) and that satisfaction with leisure activities is positively related to happiness (Freire \& Teixeira, 2018; Kaya, 2016; Kim \& Lee, 2011; Shin \& You, 2013; Wang et al., 2008). All values for skewness and kurtosis were within the range of 2 and 4, respectively, for normal distribution (Byrne, 2010; Kim et al., 2009).

\section{Construct Validity Test and Fitness Test of the Model}

Convergent validity considers how closely measurement instruments are related to the other variables of one latent variable. Construct reliability (CR) and average variance extracted (AVE) were calculated to measure convergent validity (Fornell \& Larcker, 1981; Hari et al., 2010). The values of CR above 0.7 and AVE above 0.5 are acceptable. In this study, convergent validity was acceptable because the values of CR were 0.891-0.896, with the value for leisure satisfaction close to 0.7, and the AVE values were 0.5770.869 . Discriminant validity is also acceptable because the AVE values are greater than the shared variance (i.e., squared correlation) (Fornell \& Larcker, 1981). Values around 0.08 are considered acceptable for RMSEA, while values of 0.05 are considered good; values of 0.90 or greater are considered 
good for TLI and CFI (Hu \& Bentler, 1999; Kim et al., 2009). Thus, the model fit in the current study was acceptable (female group: $\chi^{2}(\mathrm{df}=11, \mathrm{~N}=467)=29.736, \mathrm{p}=0.002, \mathrm{TLI}=0.963, \mathrm{CFI}=0.981$, RMSEA $=$ 0.060, male group: $\chi^{2}(d f=11, N=397)=28.832, p=0.002, T L I=0.954, C F I=0.976$, RMSEA $\left.=0.064\right)$.

\section{Construct Equivalence Test}

All measurement models for assessing the three latent variables were compared to verify the configural invariance. Because the metric invariance model is an inherent model in the baseline model, it can be verified through the differences in $\chi^{2}$ using the difference in degrees of freedom between the two models. The fit of Model 1, the baseline model, shows high fit indices (see Table 3) ( $\chi^{2}[\mathrm{df}=18, N=864]=41.795$, $\mathrm{p}<.001, \mathrm{TLI}=0.968, \mathrm{CFI}=0.986, \mathrm{RMSEA}=0.039)$. To verify metric invariance, which has equal factor loadings on variables across groups, the $\chi^{2}$ values and the degree of freedom of Model 2 , the metric invariance model, were compared against the baseline model, configural invariance. The difference between the $\chi^{2}$ values of the baseline model and the metric invariance model was not statistically significant at $a=0.05\left(\triangle \chi^{2}[3, N=864]=2.856\right)$ (see Table 3); thus, metric invariance was established. TLI and RMSEA in the metric invariance model were accepted because the difference in the model fit was small $(\triangle T L I=0.005, \triangle R M S E A=-0.003)$. This result indicates that the measurement tool could be applied equally to both groups. Since the metric invariance model (Model 2) was established, the next step, scalar invariance, was evaluated. The scalar invariance model (Model 3) was not established because of a statistically significant result at $a=0.05\left(\triangle \chi^{2}[6, N=864]=20.118\right)$. However, the fit indices for scalar invariance did not become worse than those for metric invariance $(\triangle T L I=-0.007, \triangle R M S E A=$ 0.004), and the scalar invariance model (Model 3) was accepted (Kim et al., 2006). The results showed that the measurement instruments and intercepts could apply equally to both groups. The observed mean differences in this study could reflect the differences between the groups for the latent variables.

\section{Latent Mean Analysis (LMA)}

Since configural, metric, and scalar invariance assumptions were all verified, LMA was carried out to see gender differences across the three latent variables (i.e., attitude toward leisure, satisfaction with leisure policy, and satisfaction with leisure activities) (see Table 4). The homogeneity of variance assumption was supported $\left(\triangle \chi^{2}[3, N=864]=14.837, p<.001, \triangle T L I=-0.006, \triangle R M S E A=0.004\right)$ according to the TLI, RMSEA, and $\chi^{2}$ difference tests comparing Models 3 and 4 (see Table 3 ). Thus, the $d$ values were calculated using common standard deviations (see Table 4). Differences in attitudes toward leisure were defined as not small ( $d=0.393$ ) based on Cohen's guidelines (Cohen, 1988; Hong, Malik, \& Lee, 2003). The results of the t-test showed no significant difference in level of happiness, an observed variable, between the female and male groups $(t=-0.201, p=0.841)$.

\section{Multigroup Structural Model Analysis}


In the multigroup structural model analysis, as a result of measuring the fitness of the path model, in which all factors for each latent variable were set the same way, the mediated model indicated a good fit with the sample data $\left(X^{2}[\mathrm{df}=25, \mathrm{~N}=864]=62.374, \mathrm{p}<.001, \mathrm{TLI}=0.964, \mathrm{CFI}=0.978, \mathrm{RMSEA}=0.042\right)$. Table 5 presents the parameter estimates for both groups. To test the significant differences between path coefficients that might exist in the female and male groups, three models with equality constraints on the three path coefficients in the model were compared with the baseline model. The model fit remained almost unchanged, even if the equality constraint was applied to all path coefficients $\left(\chi^{2}[\mathrm{df}=\right.$ $42, \mathrm{~N}=864]=1754.106, \mathrm{p}<.001, \mathrm{TLI}=0.964, \mathrm{CFI}=0.976, \mathrm{RMSEA}=0.041)$ (see Table 6). There were no statistically significant differences between the female and male groups in the equality constraints on each path. Attitude toward leisure and satisfaction with leisure policy had a strong influence on satisfaction with leisure activities; in turn, satisfaction with leisure activities had a strong influence on level of happiness for both groups. Figure 2 presents the model with equality constraints on path coefficients.

\section{Discussion}

While a substantial body of research on leisure has focused on the benefits of leisure activities among adolescents (Ahn \& Lee, 2017; Kim, 2009; Shin \& You, 2013), college students (Kim et al., 2015), and adults (Min, 2018) in Korea, it is meaningful to examine the benefits of leisure for Korean caregivers of young children because they have less chance to engage in leisure activities while parenting in Korea. In addition, caregivers' happiness plays a key role in children's well-being (Kim, 2019). Therefore, the current study aimed use SEM to explore how the effects of attitude toward leisure and satisfaction with leisure policy transferred to caregivers' happiness via the mediation of satisfaction with leisure activities using. The study also used LMA and multigroup structural analysis to explore gender differences associated with the variables and pathways.

The study results showed that a more positive attitude toward leisure and higher levels of satisfaction with leisure policy were associated with higher satisfaction with leisure activities, which was linked to higher levels of happiness. Consistent with previous research, the results support the idea that attitude toward leisure is positively related to satisfaction with leisure activities (Ahn, 2014; Choi \& Yoo, 2017; Kim, 2009; Haworth \& Lewis, 2005; Kim et al., 2015), and satisfaction with leisure policy is positively correlated with satisfaction with leisure activities (Han et al., 2019; Heo, 2014). In addition, the association between satisfaction with leisure activities and level of happiness was consistent with previous research showing that greater satisfaction with leisure activities is related to greater life satisfaction and psychological well-being (Haworth \& Lewis, 2005; Freire \& Teixeira, 2018; Kaya, 2016; Shin \& You, 2013; Wang et al., 2008). This finding suggests that caregivers for young children who had a more positive attitude toward leisure and greater satisfaction with leisure policy considered their satisfaction with their leisure activities to be beneficial for their happiness. This empirical evidence shows that satisfaction with leisure activities mediates the aspects of attitudes toward leisure and satisfaction with leisure policy that lead to greater levels of happiness. These findings are new, and they could reinforce the positive association between attitude toward leisure and satisfaction with leisure policy and 
greater happiness via satisfaction with leisure activities, especially for Korean caregivers for young children. Prior studies evaluated young adults (e.g., adolescents and college students), but this result uncovered a positive relationship in Korean family pairs. The results of this study, on the other hand, underline the important relationship between leisure experience (i.e., attitude toward leisure, satisfaction with leisure policy, and satisfaction with leisure activities) and level of happiness, for which there has been little research in Korea.

The LMA results supported the gender difference in only one variable: attitude toward leisure; the difference was not small, given the Cohen's effect size ( $d$-value $=0.393)$. In the multigroup structural analysis, attitude toward leisure and satisfaction with leisure policy had a significant indirect effect on level of happiness through the mediator of satisfaction with leisure activities for both groups; this outcome reflects full mediation. These findings indicated that female caregivers for young children had a more positive attitude toward leisure than male caregivers, but significant differences between path coefficients did not exist in either group. In general, women have more free time than men, but women's participation in leisure activities is insufficient because of the burden of child care and familial duties. As a result, the quality of women's leisure time is lower than that of men (Mattingly \& Bianchi, 2003). However, it can be assumed from the current study that the proportion of women participating in leisure activities is increasing because women's household labor has been decreasing in Korean families. These findings indicate that, although Korean females are still subject to traditional gender roles in marriage (Qian \& Sayer, 2016), their attitudes toward leisure can be positively enhanced.

In addition, the present findings underline the importance of satisfaction with leisure policy, as well as having a positive attitude toward leisure, for both female and male caregivers. In order to enhance an individual's life satisfaction, not only is personal recognition of the importance of leisure time required, but also satisfaction with leisure policies in the legal system (e.g., paid parental leave or financial support for families with children) and leisure infrastructure. Such legislation and the establishment of leisure infrastructure are important to caregivers for young children because their satisfaction with leisure activities from government-led support tends to influence their children's happiness. Therefore, leisure policy could be made to more effectively enhance the happiness of parents, especially when infrastructure, such as leisure facilities, programs, and professionals, is provided in tandem. It is believed that appropriate interventions for enhancing attitude toward leisure and satisfaction with leisure policy would help Korean caregivers perceive positive benefits from leisure activities and improve their assessments of their own happiness.

This study's importance derives from the fact that it was the first to examine the relationships between attitude toward leisure, satisfaction with leisure policy, satisfaction with leisure activities, and level of happiness in Korean caregivers for young children. However, the study had some limitations. First, it focused on Korean caregivers for young children, but did not explore the multiple demographic factors might exist that influence their satisfaction with leisure activities, such as age, educational background, income, employment, etc. It might be interesting to investigate the factors that influence satisfaction with leisure activities among parent caregivers. The second limitation is related to the nature of the

Page $10 / 20$ 
methodology used in this study. This study was designed to examine the psychological benefits gained by having a more positive attitude toward leisure and feeling greater satisfaction with leisure policy via satisfaction with leisure activities in Korean caregivers for young children; it is best not to generalize the findings. It would be beneficial for future research to qualitatively investigate the relationship between leisure experience and level of happiness among Korean caregivers for young children. Finally, this study did not differentiate between the types of Korean family structures that contain caregivers. There might be a difference in leisure activity tendencies among married parents, single parents, grandparents, etc. Future studies should investigate the relationships among the types of family structures, leisure, and happiness.

\section{Conclusion}

This study aimed to explore the structural relationships among attitude toward leisure, satisfaction with leisure policy, satisfaction with leisure activities, and level of happiness in Korean caregivers for young children. Its results show that Korean caregivers' attitudes toward leisure and satisfaction with leisure policy are important to their levels of happiness; satisfaction with leisure activities mediated the link between attitude toward leisure, satisfaction with leisure policy, and level of happiness, suggesting no gender difference. This study has advanced the literature on leisure by suggesting that satisfaction with leisure activities can promote happiness in Korean caregivers who are raising young children. The findings suggest that attitude toward leisure and satisfaction with leisure policy provide an avenue for improving satisfaction with leisure activities and facilitating happiness.

\section{Declarations}

Compliance with Ethical Standards

Ethical Approval: Ethical review for this study were waived because the data is secondary data (Approval Number is 113014).

Informed Consent: Informed consent was obtained from all individual participants included in the study.

Conflict of Interest: The authors declare that they have no conflicts of interest.

Funding: The author(s) received no financial support for the research, authorship, and/or publication of this article.

Data Availability Statement: Data are available upon request from the corresponding author. Data from this study originated from the National Leisure Activities Survey of Korea 2018.

\section{References}


1. Ahn., B. W. (2014). The Verification of Relationship Model among Leisure Motivation, Flow, Constraint, Attitude, Satisfaction by Foreigners' Leisure Activity Participation in Korea. Journal of Wellness, 9(4), 13-25.

2. Ahn, H-K \& Lee, M-K. (2017). Relationships between Social Support and Psychological Well-Being according to Leisure Attitudes of Middle and High School Student. Journal of Korean Society for Wellness, 12(3), 185-198.

3. Aslan, Nese. An examination of family leisure and family satisfaction among traditional Turkish families. Journal of Leisure Research, 41(2), 157-176.

4. Ateca-Amestoy, V. (2011). Leisure and subjective well-being. In S. Cameron (Ed.), Handbook on the economics of leisure (pp. 52-76). Northampton, MA: Edward Elgar.

5. Beard, J. G., \& Ragheb, M. G. (1980). Measuring leisure satisfaction. Journal of Leisure Research, (1), 20-33.

6. Byrne, B. M. (2010). Structural equation modeling with AMOS: Basic concepts, application and programming. New York: Routledge.

7. Cho, D. (2017). Analytical Concept of Happiness and Its Measurement. Journal of Labour Economics, 40(3), 79-104.

8. Cho, M.-K. (2015). An Empirical Study on the Factors of Leisure Activity for the Effectiveness of Leisure Policy (Unpublished doctoral dissertation) University of Seoul.

9. Choi, K.-R.(2002). The influence of family leisure activities on emotional dynamics and quality of family relationships (Unpublished doctoral dissertation unpublished) Dongduk Women's University.

10. Choi, S., \& Yoo, Y. (2017). Leisure attitude and satisfaction with leisure and life: proposing leisure prioritization and justification. World Leisure Journal, 59, 140-155.

doi:10.1080/16078055.2016.1216886

11. Cohen, J. (1988). Statistical power analysis of the behavioral sciences (2nd ed.). Lawrence Erlbaum Associates, Publishers.

12. Diener, E., Lucas, R. E., \& Oishi, S. (2002). Subjective well-being: The science of happiness and life satisfaction. Handbook of positive psychology, 2, 63-73.

13. Doh, N. (2014). Sufficient leisure time must be guaranteed for the happiness of infants and toddlers. KICCE Policy Brief, 24, 1-4

14. Doh, Y. Y., \& Chung, J. B. (2020). What Types of Happiness do Korean Adults Pursue?-Comparison of Seven Happiness Types. International journal of environmental research and public health, 17(5), 1502. https://doi.org/10.3390/ijerph17051502

15. Edginton, C. R., \& Chen, P. (2008). Leisure as transformation. Sagamore Publishing.

16. Fornell, C., \& Larcker, D. F. (1981). Evaluating structural equation models with unobservable variables and measurement error. Journal of Marketing Research, 18(1), 39-50.

https://doi.org/10.1177/002224378101800104 
17. Freire, T., \& Teixeira, A. (2018). The Influence of Leisure Attitudes and Leisure Satisfaction on Adolescents' Positive Functioning: The Role of Emotion Regulation. Frontiers in psychology, 9, 1349. https://doi.org/10.3389/fpsyg.2018.01349

18. Frey, B. S., \& Stutzer, A. (2002). What can economists learn from happiness research?. Journal of Economic literature, 40(2), 402-435.

19. Han, J., Jung, D., \& Lee, J. (2019). An Empirical Study on Satisfaction of Public Leisure Facilities and Leisure Life: Mediating Effect of Leisure Policy Satisfaction. Journal of Leisure Studies, 17(2), 6185.

20. Hari, J. F. Jr., Black, W. C., Babin, B. J., \& Anderson, R. E. (2010). Multivariate data analysis (7th ed.). Englewood Cliffs, NJ: Prentice-Hall.

21. Haworth, J., \& Lewis, S. (2005). Work, leisure and well-being. British Journal of Guidance \& Counselling, 33(1), 67-79.

22. Helliwell, J. F., Layard, R., \& Sachs, J. D. (2019). World Happiness Report 2019. New York, NY: Sustainable Development Solutions Network.

23. Heo, C. U. (2014). Satisfaction and Constraints on Leisure Activities Participation among the Leisure Facilities User in Korea. International Journal of Tourism and Hospitality Research, 28(12), 203-213.

24. Holman, T. B., \& Jacquart, M. (1988). Leisure activity patterns and marital satisfaction: A further test. Journal of Marriage and the Family, 50, 69-78.

25. Hong, S. H., Malik, M. L., \& Lee, M. K. (2003). Testing configural, metric, scalar and latent mean invariance across genders in sociotropy and autonomy using a non-western sample. Educational and Psychological Measurement, 63 (4), 636-654.

26. Hu, L. Z., \& Bentler, P. M. (1999). Cutoff criteria for fit indexes in covariance structure analysis: Conventional criteria versus new alternatives. Structural Equation Modeling: A Multidisciplinary Journal, 6, 1-55.

27. Jeong. K. \& Won, C. (2002). Relationship of lifestyle, leisure, recognition and leisure satisfaction. International Journal of Tourism Management and Sciences, 17(2), 23-41.

28. Jeung, Y-K. \& Yoon, S-Y. (2014). Impact of leisure activity on the leisure economy of Korean babyboomers. Korea Family Resource Management Association,18(3), 61-77.

29. Jung, H., Kwon, J., Jeong, S., Kim, S., Chun,Y., Kwon, S., ... Yu, J. (2019). A Comprehensive Study of Happiness and Quality of Life in Korea. Seoul, Korea: KIHASA.

30. Kaya, S. (2016). The relationship between leisure satisfaction and happiness among college students. Universal Journal of Educational Research, 4(3), 622-631.

31. Kim, J., Kim, M., \& Hong, S. (2009). Structural Equation Modeling in Dissertation. Seoul: Communication Books.

32. Kim., K. (2019). The Effect of Parent's Happiness and Parenting Stress on Parenting Attitude. Korean Journal of Child Care and Education, 116, 1-20. 
33. Kim, K. \& Lee, R. (2011). Leisure Activities, Leisure Satisfaction and Happiness among the Korean: Utilizing Data of National Statistics. The Journal of the Korea Contents Association, 11(11), 424433.

34. Kim, M. S., Kim, H. W., Han, Y. S., \& Im, J. Y. (2003). Explorations on the happy life of Koreans on the bases of their social structural variables. The Korean Journal of Psychology: General, 22(2), 1-33.

35. Kim, Sun-H. (2009). Relation between adolescents' level of involvement in recreational activities and emotional expression and confidence for recreation. Journal of Leisure and Recreation Studies, 33(2), 135-144.

36. Kim, S-S. (2008). A study on the effect of leisure satisfaction, leisure commitment on psychological well-being and self-actualization (Unpublished doctoral dissertation) Anyang University.

37. Kim, S., Sung, J., Park, J., \& Dittmore, S. W. (2015). The relationship among leisure attitude, satisfaction, and psychological well-being for college students. Journal of Physical Education and Sport, 15(1), 70.

38. Leitner, M. J., \& Leitner, S. F. (2004). Leisure enhancement. Haworth Press.

39. Lee, J.-H. (2005). Relationship between the quality of life by the leisure activity of high school students. Korea Sport Research, 16(5), 1483-1490.

40. Lee, R.-J. (2010). The Study on the Relations in between the Leisure Activity, Leisure Satisfaction and Life Satisfaction of College Student. Journal of Tourism Studies, 22(2), 155-178.

41. Mattingly, M.J., \& Bianchi, M. (2003). Gender Differences in the Quantity and Quality of Free Time: The U.S. Experience. Social Forces, 81, 1030 - 999.

42. McMahon, D. M. (2006). Happiness: A history. New York: Grove.

43. Meyer, B. \& Niezgoda,A.(2018). The Impact of the Perception of Leisure on Recreational and Tourism Spaces in an Urban Area. Tourism, 28(1), 47-52. https://doi.org/10.2478/tour-2018-0006

44. Ministry of Culture, Sports, and Tourism. (2016, April 27). 2016 Survey on National Leisure Activity. Retrieved from https://www.mcst.go.kr/kor/s_policy/dept/deptView.jsp?pSeq=1662\&p

45. Min, K. (2018). Leisure and Life Satisfaction among the Work-Life Balance Generation. Journal of the Korean society for Wellness, 13(3), 377-388.

46. Moon, H. (2001). A Study of Parental Satisfaction and Child-Rearing Practices. Journal of the Korean Home Economics Association, 39 (1), 205-219.

47. Myers, D. G., \& Diener, E. (1995). Who is happy?. Psychological science, 6(1), 10-19.

48. Orthner, D. K., \& Mancini., J. A. (1990). Leisure impacts on family interaction and cohesion. Journal

49. of Leisure Research, 22, 123-137.

50. Qian, Y., \& Sayer, L. C. (2016). Division of labor, gender ideology, and marital satisfaction: A comparative analysis of mainland China, Japan, South Korea, and Taiwan. Journal of Marriage and Family, 78(2), 383-400. https://doi.org/10.1111/jomf.12274

51. Ragheb, M. G., \& Griffith, C. A. (1982). The contribution of leisure participation and leisure satisfaction to life satisfaction of older persons. Journal of Leisure Research, 18, 248-258. 
52. Ragheb, M. G. \& Beard, J. G. (1982). Measuring leisure attitude. Journal of Leisure Research, 14, 155-167. doi: 10.1080/00222216.1982.11969512

53. Ragheb, M. G., \& Tate, R. L. (1993). A behavioural model of leisure participation, based on leisure attitude, motivation and satisfaction. Leisure Studies, 12(1), 61-70.

54. Riddick, C. C. (1986). Leisure satisfaction precursors. Journal of Leisure Research, 18, 259-265.

55. Seligman, M. E. P. (2002). Authentic happiness. New York: Free Press.

56. Shin, K., and You, S. (2013). Leisure type, leisure satisfaction and adolescents' psychological wellbeing. Journal of Pacific Rim Psychology, 7, 53-62. doi: 10.1017/prp.2013.6.

57. Son, J.-Y. (2017). A Effect of Leisure Participating older adults Leisure Satisfaction as a Leisure Participant on Psychological Wellbeing. The Journal of the Korea Contents Association, 17(9), 536548.

58. Stebbins, R. (2009). Serious Leisure and Work. Sociology Compass 3(5), 764-774, 10.1111/j.1751-2009.00233.x.

59. The World Bank. (2021, April 14). World Bank GDP Per Capita (Current US\$). Retrieved from https://data.worldbank.org/indicator/NY.GDP.PCAP.CD .

60. Teixeira, A., \& Freire, T. (2013). The leisure attitude scale: Psychometrics properties of a short version for adolescents and young adults. Leisure/Loisir, 37(1), 57-67.

61. Veblen, T. (1994). The Theory of the Leisure Class. New York: Dover Publications.

62. Wang, E., Chen, L., Lin, J., and Wang, M. C. (2008). The relationship between leisure satisfaction and life satisfaction of adolescents concerning online games. Adolescence, 43, 177-184.

63. Zabriskie, R. B., \& McCormick, B. (2003). Parent and child perspectives of family leisure involvement and satisfaction with family life. Journal of Leisure Research, 35, 163-189.

64. Zabriskie, R. B., \& McCormick, B. (2003). Parent and child perspectives of family leisure involvement and satisfaction with family life. Journal of Leisure Research, 35, 163-189.

\section{Tables}

Table 1 Leisure types by participants 


\begin{tabular}{|c|c|c|}
\hline Leisure Type & Frequency & $\%$ \\
\hline Cultural and Art-Viewing Activities & 18 & 2.1 \\
\hline Exhibition & 1 & .1 \\
\hline Concert & 2 & .2 \\
\hline Theater & 4 & .5 \\
\hline Movie & 11 & 1.3 \\
\hline Cultural- and Art-Participation Activities & 98 & 11.1 \\
\hline Musical instrument/singing class & 3 & .3 \\
\hline Photoshoot & 2 & .2 \\
\hline Indirect sports watching (TV or DMB) & 12 & 1.4 \\
\hline Basketball, baseball, volleyball, soccer & 2 & .2 \\
\hline Tennis, squash & 1 & .1 \\
\hline Billiards & 3 & .3 \\
\hline Bowling, table tennis & 1 & .1 \\
\hline Golf & 1 & .1 \\
\hline Swimming & 5 & 6 \\
\hline Fitness exercise, aerobics & 38 & 4.4 \\
\hline Yoga, Pilates & 20 & 2.3 \\
\hline Badminton, jump rope & 8 & .9 \\
\hline Tae kwon do, judo & 2 & .2 \\
\hline Tourism & 8 & .8 \\
\hline Visiting cultural heritage sites & 1 & .1 \\
\hline Camping & 3 & .3 \\
\hline Picnicking & 1 & .1 \\
\hline Amusement park & 2 & .2 \\
\hline Driving & 1 & .1 \\
\hline Hobbies and Entertainment Activities & 248 & 28.6 \\
\hline Crafts & 3 & .3 \\
\hline Cooking & 10 & 1.2 \\
\hline
\end{tabular}

Page 16/20 


\begin{tabular}{|c|c|c|}
\hline Pets & 5 & .6 \\
\hline Climbing & 1 & .1 \\
\hline Fishing & 1 & .1 \\
\hline Internet surfing, SNS chatting & 158 & 18.3 \\
\hline Internet games, PSP, PS3, Nintendo & 47 & 5.4 \\
\hline Board game & 2 & .2 \\
\hline Shopping & 6 & .7 \\
\hline Drinking & 4 & .5 \\
\hline Skin care, beauty-related activities & 1 & .1 \\
\hline Reading books, watching cartoons & 6 & .7 \\
\hline Learning languages & 1 & .1 \\
\hline Gardening & 3 & .3 \\
\hline Relaxation Activities & 437 & 50.6 \\
\hline Walking & 32 & 3.7 \\
\hline Sauna & 5 & .6 \\
\hline Napping & 1 & .1 \\
\hline Watching TV (DMB, IPTV) & 368 & 42.6 \\
\hline Watching videos (DVD, VOD) & 5 & .6 \\
\hline Listening to radio (podcast) & 4 & .5 \\
\hline Listening to music & 20 & 2.3 \\
\hline Newspaper or magazine reading & 1 & .1 \\
\hline Doing nothing & 1 & .1 \\
\hline Social and Other Activities & 45 & 5.2 \\
\hline Community service activities & 1 & .1 \\
\hline Religious activities & 5 & .6 \\
\hline Talking in person or on the phone & 36 & 4.2 \\
\hline Dating & 1 & .1 \\
\hline Meeting friends & 2 & .2 \\
\hline
\end{tabular}


Note. Selected by allowing duplicates.

Table 2 Correlations, mean values, standard deviation, skewness, and kurtosis of variables.

\begin{tabular}{|c|c|c|c|c|c|c|c|}
\hline Variables & 1 & 2 & 3 & 4 & 5 & 6 & 7 \\
\hline $\begin{array}{l}\text { 1. Attitude toward } \\
\text { Leisure } 1\end{array}$ & 1 & 0.768 ** & -0.030 & -0.035 & 0.128 ** & 0.077 & $0.192^{\star \star}$ \\
\hline $\begin{array}{l}\text { 2. Attitude toward } \\
\text { Leisure } 2\end{array}$ & 0.650 ** & 1 & -0.001 & -0.022 & 0.086 & $0.161^{* *}$ & $0.226^{\star \star \star}$ \\
\hline $\begin{array}{l}\text { 3. Satisfaction with } \\
\text { Leisure Policy } 1\end{array}$ & 0.018 & 0.007 & 1 & $0.789 * *$ & $0.194 * \star$ & $0.169 * *$ & 0.068 \\
\hline $\begin{array}{l}\text { 4. Satisfaction with } \\
\text { Leisure Policy } 2\end{array}$ & 0.044 & 0.004 & $0.791^{\star \star}$ & 1 & $0.169 * \star$ & $0.177^{\star \star *}$ & $0.094^{\star}$ \\
\hline $\begin{array}{l}\text { 5. Satisfaction with } \\
\text { Leisure Activities } 1\end{array}$ & 0.091 & 0.083 & $0.173^{\star \star}$ & $0.137^{\star *}$ & 1 & $0.112^{*}$ & $0.288^{\star *}$ \\
\hline $\begin{array}{l}\text { 6. Satisfaction with } \\
\text { Leisure Activities } 2\end{array}$ & $0.234^{\star \star}$ & $0.234^{\star}$ & $0.245^{\star \star}$ & $0.239 * *$ & 0.087 & 1 & $0.142^{\star \star}$ \\
\hline 7. Happiness & $0.255^{\star \star}$ & $0.295^{\star \star}$ & $0.166^{\star \star}$ & $0.211^{\star \star}$ & $0.295^{\star \star}$ & 0.164 ** & 1 \\
\hline \multirow[t]{2}{*}{$M(S D)$} & 5.45 & 5.58 & 4.75 & 4.91 & 5.54 & 4.18 & 6.89 \\
\hline & $(0.88)$ & $(0.85)$ & $(0.98)$ & $(0.92)$ & $(0.94)$ & $(1.20)$ & $(1.42)$ \\
\hline Skewness & -0.139 & -0.140 & -0.212 & -0.362 & -0.297 & -0.253 & -0.530 \\
\hline Kurtosis & 0.025 & -0.224 & 0.089 & 0.392 & -0.042 & -0.306 & 0.673 \\
\hline
\end{tabular}

Note. ${ }^{*} p<.05,{ }^{*} p<.01$. The upper triangular matrix represents the correlation values for the female group, and the lower triangular matrix represents the correlation values for the male group.

Table 3 Fit indices for invariance tests

\begin{tabular}{|lllllll|}
\hline Model & $\chi^{\mathbf{2}}$ & df & $\mathbf{p}$ & TLI & CFI & RMSEA \\
\hline $\begin{array}{l}\text { Configural invariance (baseline model): Model } \\
1\end{array}$ & 41.795 & 18 & 0.001 & 0.968 & 0.986 & 0.039 \\
\hline Metric invariance: Model 2 & 44.651 & 21 & 0.002 & 0.973 & 0.986 & 0.036 \\
\hline Metric \& scalar invariance: Model 3 & 64.769 & 27 & 0.000 & 0.966 & 0.978 & 0.040 \\
\hline $\begin{array}{l}\text { Metric, scalar \& factor variance invariance: } \\
\text { Model 4 }\end{array}$ & 79.606 & 30 & 0.000 & 0.960 & 0.971 & 0.044 \\
\hline
\end{tabular}

Table 4 Results of latent mean analysis 


\begin{tabular}{|c|c|c|c|c|c|c|}
\hline \multirow[b]{2}{*}{ Latent variables } & \multicolumn{2}{|c|}{ Female $(n=467)$} & \multicolumn{2}{|c|}{ Male $(n=397)$} & \multirow[b]{2}{*}{$\begin{array}{l}\text { Effect } \\
\text { size }\end{array}$} & \multirow[b]{2}{*}{$\begin{array}{l}\text { Total } \\
\text { M }\end{array}$} \\
\hline & $\begin{array}{l}\text { Latent } \\
\mathrm{M}\end{array}$ & M & Latent M & M & & \\
\hline Attitude toward Leisure & 0 & 5.609 & $-0.195^{\star \star \star}$ & 5.406 & 0.393 & 5.516 \\
\hline Satisfaction with Leisure Policy & 0 & 4.830 & -0.004 & 4.826 & 0.006 & 4.828 \\
\hline $\begin{array}{l}\text { Satisfaction with Leisure } \\
\text { Activities }\end{array}$ & 0 & 4.827 & -0.060 & 4.900 & 0.007 & 4.859 \\
\hline Happiness & n.a. & 6.900 & n.a. & 6.880 & 0.001 & 6.890 \\
\hline
\end{tabular}

Note. The latent mean values for females were fixed to zero. ${ }^{\star \star \star} \mathrm{p}<.001$.

Table 5 Parameter estimates for female and male Groups (model with equality constraint on factor loading)

\begin{tabular}{|lll|}
\hline Parameter & Female & Male \\
\hline Attitude toward Leisure $\rightarrow$ Satisfaction with Leisure Activities & $0.203^{\star \star \star}$ & $0.320^{\star \star \star}$ \\
& $(0.405)$ & $(0.564)$ \\
\hline $\begin{array}{l}\text { Satisfaction with Leisure Policy } \rightarrow \text { Satisfaction with Leisure } \\
\text { Activities }\end{array}$ & $0.159 \star \star \star$ & $0.190 \star \star \star$ \\
\hline Leisure Satisfaction $\rightarrow$ Happiness & $(0.355)$ & $(0.459)$ \\
& $1.928^{\star \star \star}$ & $2.218^{\star \star \star}$ \\
\hline
\end{tabular}

Notes. Parameter estimates are unstandardized coefficients. Standardized coefficients are given in parentheses. ${ }^{* \star *} \mathrm{p}<.001$.

Table 6 Comparison of female and male group differences between the baseline model and models with equality constraints on the path coefficients

\begin{tabular}{|lllll|}
\hline Path with equality constraint on path coefficient & $\Delta \mathbf{d f}$ & $\boldsymbol{\Delta} \mathbf{X}^{2}$ & $\mathbf{p}$ & $\Delta$ TLI \\
\hline Attitude toward Leisure $\rightarrow$ Satisfaction with Leisure Activities & 1 & 3.2 & 0.074 & 0.001 \\
\hline $\begin{array}{l}\text { Satisfaction with Leisure Policy } \rightarrow \text { Satisfaction with Leisure } \\
\text { Activities }\end{array}$ & 1 & 0.305 & 0.581 & -0.002 \\
\hline Satisfaction with Leisure Activities $\rightarrow$ Happiness & 1 & 0.302 & 0.583 & -0.002 \\
All constrained & 3 & 6.777 & 0.079 & -0.001 \\
\hline
\end{tabular}

\section{Figures}




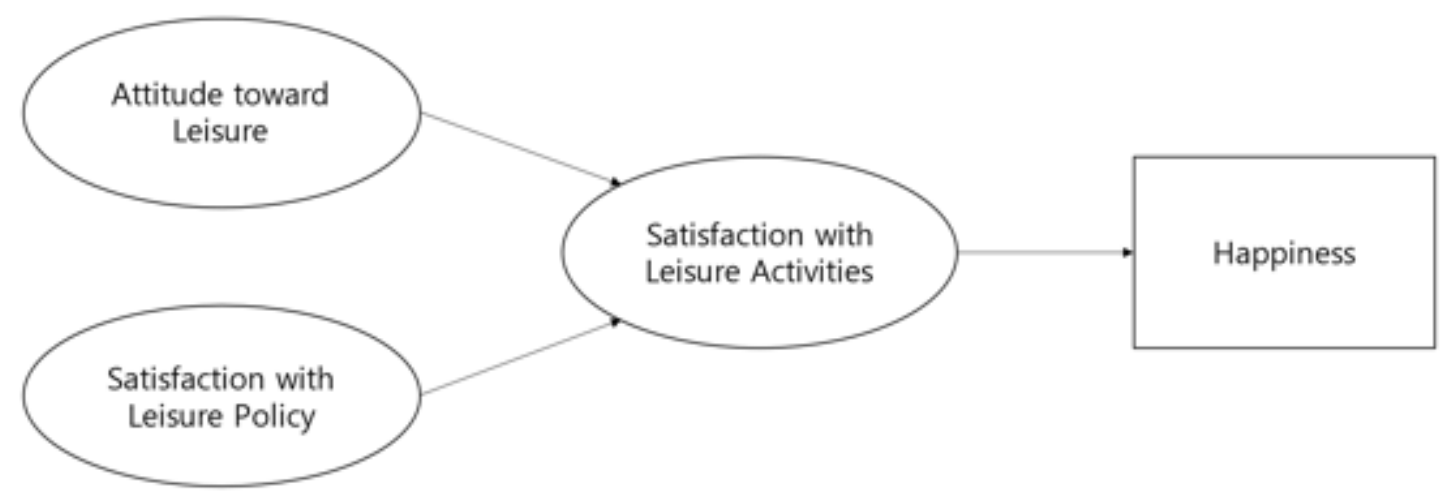

\section{Figure 1}

Path Diagram of the Hypothesized Model.



\section{Figure 2}

Model with equality constraints on factor loadings and path coefficients (standardized coefficients are shown for females and then males: ${ }^{* *} p<.001$ ) 